\title{
The Study on Efficient Cold Chain Logistics
}

\author{
Zhang Yu \\ School of Economics and Management, Chang'an \\ University, Xi'an, China \\ Syed Abdul Rehman Khan \\ School of Economics and Management, Tsinghua \\ University, Beijing, China
}

\author{
Ma Tianshan \\ School of Economics and Management, Chang'an \\ University, Xi'an, China \\ Arshian Sharif \\ Othman Yeop, Abdullah Graduate School of Business, \\ Universiti Utara Malaysia
}

\begin{abstract}
In the supply chain, cold chain is a small part, usually cold chain are using for frozen foods, medical supplies, and fragile items such as, meat, medicines, ice cream, fish etc. The concept of RFID (radio frequency identification device) is tracking products/containers. This technology widely used in the cold supply chain for tracing trucks and their temperature. On the other hand, sensors and RFID is new technology, which also boost to the field of cold chain logistics. This research conducted to find the usage of sensors and RFID and their advantages. The system has many advantages to apply it and it experiences low cost of overhead. For the consideration of differentiated marketing strategy, it is a good strategy to apply this guaranteed cold chain. The LTE-A, the future of GPS and 3G technologies combined with the concept of extranet and intranet make it more transparent for the customers so that the customer can believe the products certainly. A broad and detailed standard of that system needs to be advised in detail so that the suppliers, customers and vendors can follow it bitterly and can more collaborative on the behalf of this system.
\end{abstract}

Keywords-RFID; Sensors; Supply chain management; Cold chain logistics

\section{INTRODUCTION}

In the supply chain, cold chain refers to a systematic logistics program, which are the temperature sensitive products are always delivered and keep in the cold (low temperature) environment in the whole process, for example: storage, production, transportation, distribution and marketing to ensure quality $\&$ safety foods, quick delivery and reduce wear and tear of logistics. Usually cold chain depends on four aspects of frozen storage, frozen processing, refrigerated transportation and distribution, and finally frozen sales (Zhang, 2007). Typically cold chain (sensitive products) products include fresh food, dairy products, vaccines, blood etc. Bo \& Danyu, (2009) and Mohan et al. (2017) some foods such as pieces of fish needs difficult and rigorous meat processing, warehousing and transportation to guarantee its freshness and quality. Due to the high-end consumers, this guaranteed fresh quality is very important. Cold supply chain is a complete supply chain, which ensures that the cores needs requirements of maintaining cold (low) temperature environment for the reason to safe and maintain quality of perishable foods. Cold chain required huge investment and special treatment as compare to normal logistics systems.
In this research, we proposed the RFID's applications, $3 \mathrm{G}$ or long term evolution (LTE) of Universal Mobile Telecommunication System (UMTS) networks and sensor networks to ensure the transparency described in the last paragraph. The RFID's application can maintain data of lot ID and sensed temperatures issued by sensors in packages during the packaging, transportation and storage. The RFID readers are installed in the fixed side of transportation line. These readers, which are in the fixed side of transportation line, that are used to induce the reading tag on lot cases when sent to the truck (transportation). The communication units in refrigerated truck are used to send the temperature data (real-time) issued by the sensor of pack periodically to the data servers. The web server publishes all the data of foods products ordered by the customer, when the customer logs in the extranet of suppliers. GPS (Global Positioning System) receiver if includes by communication's units, the vehicles for the transportation can reports its position piggybacked to these sensed temperature data. Some benefits of this extra device are that the high value vehicles can be traced easily (in the case of kidnapping etc.)

\section{RADIO FREQUENCY IDENTIFICATION DEVICE}

For the UPC (Universal Product Code), RFID has been become a feasible and viable replacement in various industries. It is very fast growth and huge potential advantages motivated a major move taken by the world's largest retailer "Wal-Mart", as well DoD (the US department of defence), that requires their suppliers to used RFID tags by 2005 (Talyor et al. 2014; Maurizio \& Francesca, 2007). Radio Frequency Identification Device (RFID) is totally based on radio frequency signal (RF) to make an automatic identification on moving products as well exchange digital info (Abbasi et al. 2016; Jian, 2006) RFID majorly consist of three parts, including readers, antennas and tags which are shown in figure 1. 


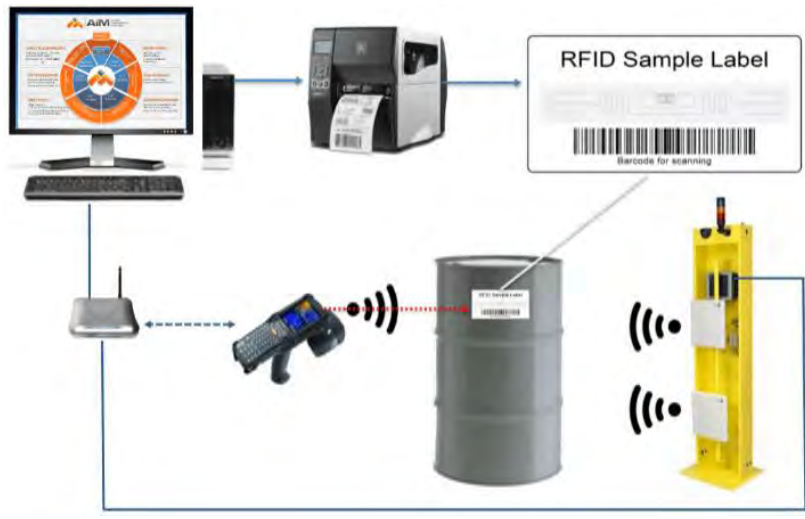

Fig. 1 RFID System Components

At its simplest form, a tag is an ideal and beacon announcing its presence to reader. These types' tags are usually used in retail stores to prevent from theft's activities. The capabilities of RFID, however, extend well beyond a simple beacon. In used, for inventory management on the global scale, like as a UPC, tag can have a UID (unique identity) of 8 bytes. A tag carry rewriteable persistent storage and accessible by a reader.

RFID tags are categorized by its power \& energy source including

A. Active Tag

RFID active tag its own has battery power to perform all operations.

\section{B. Semi Active or Semi Passive}

RFID semi-passive tag its own has battery to use for some operations \& functions.

\section{Passive tag}

RFID passive tag its own has no battery and use by the incoming radio frequency waves, which broadcast by a reader.

Generally, radio frequency identification device (RFID) fall into two main categories including HF (high frequency) and UHF (ultra-high frequency)

HF (high frequency) systems follow to the standard of ISOs, while UHF systems still not become standardized globally (Zhen et al. 2007).

RFID, tags have a large data storage, which can be used to store temperature's data during the storing, processing, receiving and transporting action. The one trick of this system is that's, the RFID tag is easy to operate, can use multiple times and also low cost. Usually it can be written and read in the range of 30 meters from RFID reader (depending on the tag's type).

RFID can provide an ID code, and nonstop records about temperature data with real time, facilitate the retrospective info and easier to define the responsibility. Even management, if the sensed temperatures received by the server (database) are abnormal meanwhile it violates the already defined criteria in the standard operation procedure, which may initiate an event we set in the record and system of MIS, and the system issue a message of warning to the supervisor to get clear of this issue. And this is "called Event Management".

\section{ARCHITECTURE}

Cold Chain has four stages refrigeration processing, refrigeration distribution refrigeration storage and refrigeration sale. And in every stage, there are standard operation procedures to ensure the safety and quality of the foods from the processing till to customers or consumers. The system perspective in each stage is addressed in the following subdivisions.

\section{A. Refrigerated Storage and Processing Stag}

The RFID sensor on the package case will be initiated at the starting moment of processing level or stage. And from this situation, the sensor with RFID will record the temperature and timestamp in the memory of that RFID and will send this data towards the RFID (reader) of the processing centre. It is noticeable that human-being cannot live in the very cold temperature like -18 degree, so it is very important for the operator to start and process the raw material under low temperature but it should be greater than -18 degree within a limited duration. For every batch operation, one EPC code is generated and traced by the sensor with RFIDs EPC code.

In the frozen (very cold temperature) processing centre, the sensed timestamp and data will be sent out periodically basis to the RFID reader in this centre. And all the data will be conveyed to the database server. In that scenario, the database server will judge if there are any time of abnormal condition, situation according to the rule of temperature of processing centre. The concept of this refrigerated storage and processing centre is shown in figure 2.

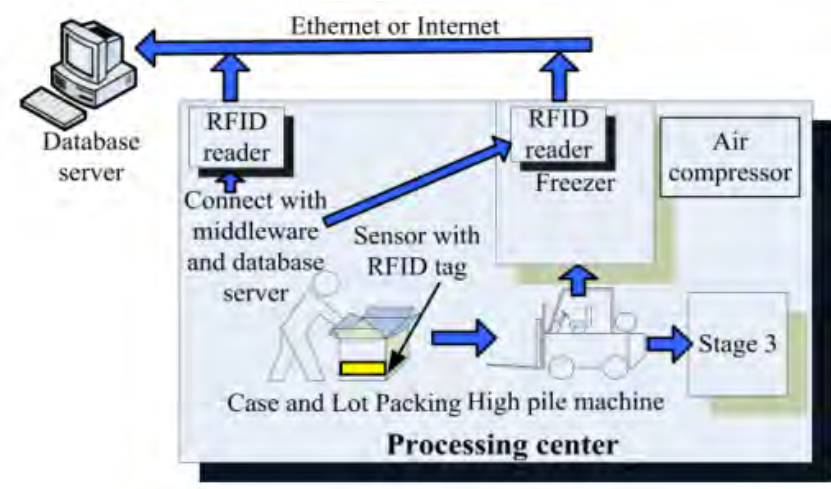

Fig. 2 The Concept of Storage and Processing Centre

\section{B. Sale and Transportation Stage}

One time if the cold chain foods have been dispatch from the frozen storage or processing centre, these foods will be sent to the truck by a high pill machine or transportation line. The transportation line can be walk to the truck or a mechanical line. But there will be RFID reader attached and involved on this line. Whenever the lot packs dispatch out by the line in the range of induction, the RFID reader will alarm and send the EPC of this vehicle number, lot pack to the database server to clue their relationship. One time when the customer log in the web server and make a query regarding the condition of their ordered foods, all the details will be shown in detail, including the frozen 
conditions. The customer's server of database can receive this data stream to monitor the foods quality in any place and at any time. Therefore, one time the cold chain foods are received, the maintain quality of those foods has been determined by the customer's database server. The server can place very strict rules on this data stream, and if any violations occur, the customer can reject or cancel the foods' order before arrival of those foods. On the same time, the supplier's database server will also make an event notice to the supervisor, and the RFID reader over the truck can also occur warning message to the truck's driver if the air compression over that truck is out of order. This innovation can provide to the customers' guaranteed quality. And it is also a best marketing strategy to make a differentiation from competitor's cold chain logistics.

In fact, if an RFID (radio frequency identification device) tag is given sensing capabilities, the line between sensor network and RFID becomes unclear. Lots of active and semipassive tags have incorporated sensors into their design, permitting them to take sensor readings and transmit them towards reader at a later time. Loc, (2005); Zhen et al. (2007); Lee et al. (2015) they are not quite sensor network nodes because they lack of the capacity to communicate with one another by a cooperatively formed network (ad-hoc), but they are outside simple RFID tags storage. In this way RFID (radio frequency identification device) is converging with the technology of sensor networking. Mateusz, (2007) defined cargonet, a system of low cost, micro power sensor active tags that pursues, seeks to bridge the current gap between RFID and wireless sensor networks. On the other hand, some sensor nodes are also using RFID readers as for their sensing capabilities. Th SkyeRead Mini M1 made by SkyeTek is an example of an RFID reader designed to mate directly with the Crossbow Mica2Dot Sensor motes. Khademian and Bagherpour, (2017) it should be noted that, the sensor networks in the freezer, processing centre and frozen storage in trucks are simple to be one-hop. The transfer of data can be achieved by sensor networks or the initiated of RFID reader, due to the distance between reader and tag is not very long, such as less than 3 meters. If there are 30 lot containers over the truck, and only one lot container's temperature is not normal to be received, we can judge it that the sense function of that sensor is out of order. This way abnormal sensor should be verified in the loading procedure to the truck if the sensed data is not normal on that time. As to the data transmission, 4G technologies like WiMAX and LTE offer high bandwidth for the data transfer. The uplink data rate of the future 4G can be up to several Megabits / seconds (Mbps). If there are total 100 records of sensed data / minute to be sent by $3 \mathrm{G}$ or $4 \mathrm{G}$ in the truck, the required throughput of those data stream is 960 bps. If we assume the sizes of EPC, GPS position, Coded Temperature and other necessary data are 64, 8, 16 and 8 bits, correspondingly.

Hence, even the low data rate of the $3 \mathrm{G}$ network can afford this traffic transmission definitely. The telecommunication firm, Estisalat Telecom in UAE claims that now they can offer the data rate more than $10 \mathrm{Mbps}$ for the $3.5 \mathrm{G}$, HSDPA (high speed downlink packet access). In this complete network, the data dispatch from the truck can be denser, i.e. estimated rate is 1600 bps and sending the sensed data per 10 seconds. Hence, the transmission time is short to 0.0016 seconds. If we assume the data rate is more than $100 \mathrm{Mbps}$. If total 100 trucks for transportation, the required throughput can be $160 \mathrm{Kbps}$. The computation loading for that data processing is definitely light for the database server.

\section{DISCUSSION}

\section{A. Marketing Strategy}

As we have mentioned in the last parts, this guaranteed lowtemperature logistics be a best strategy of marketing for differentiated marketing. The definition of differentiated marketing is strategy of sales growth in which population segments, several market niches are targeted with different products for every segment. So this guaranteed low temperature logistics will be treated as a different items for the quality guaranteed and niches of transparency for the customers. Although this strategy is not very costly to initiate, it cannot be sustained competency. Nevertheless, the first mover in that innovation strategy can gain (first mover advantage) benefits, trust and good brand name, image for the customers from the potential, prospective of CRM (customer relationship management). At least, this differentiated marketing is expected to generate value in the short term.

\section{B. Economic and Cost Benefits}

The basic obstacle to use RFID is high cost, as compare with bar code system. Regardless of the possible condition to produce the RFID chip massively, the cost of bar code is still cheaper than RFID system. Because the bar code system cost is nearly zero. Therefore, the deployment of RFID (radio frequency identification device) on the merchandise of the supermarket is evaluated to be impossible generally. From the perspective of environmental protection, commercial RFID might be an impact over environment. Luckily, all the RFID chips are useable, which used in that guaranteed logistics of cold-chain. So the cost of RFID reader and tag is not a concern here. As the cloud computing is developing; the cost of $3 \mathrm{G}$ or $3.5 \mathrm{G}$ will be lower. Due to the increase of market demands. That marvellous increase in need for the technique of cloud computing will run, drive the cost down of the communication infrastructure because off the factor of economic of scale.

In summary, the cost of this guaranteed system is not expensive and should be practical in all logistics' cold chain. As well the economic advantages to implement this system, it is valuable by applying the known the strategy of 4Ps marketing. The system, which guarantees the logistics' cold chain, will let those customers pay greater cost to taste Sashimi (fresh fish sliced) transported. The economic advantages of that system are valuable many to evaluate.

\section{Traceability}

Nowadays, food safety and quality is highly concern by various countries, RFID has the complete feature of traceability to promote food safety and ensure in some complex chain of supply, especially in cold chain (temperature sensitive) foods. For industries, it will enhance the competitiveness of enterprises and operating efficiency (internally). For people, they will have more confidence regarding health and hygiene. 


\section{CONCLUSION}

In this research study, cold chain logistics (temperature sensitive) is proposed. The system has various advantages to apply it and it experiences low cost of overhead. For the consideration of differentiated marketing strategy, it is a good strategy to apply this guaranteed cold chain. The LTE-A, the future of GPS and $3 \mathrm{G}$ technologies combined with the concept of extranet and intranet make it more transparent for the customers so that the customer can believe the products certainly. A broad and detailed standard of that system needs to be advised in detail so that the suppliers, customers and vendors can follow it bitterly and can more collaborative on the behalf of this system.

\section{ACKNOWLEDGEMENT}

This research was financially supported by Scientific Innovation Practice Project of Postgraduate of Chang'an University, Xi'an, Shaanxi, China, 710064.

\section{REFERENCE}

[1] B Maurizio, L. Francesca, M. Francesca, (2007). "Instant Collision resolution for tag identification in RFID networks", Ad Hoc Networks, Vol. 5, No. 8, PP. 1220-1232.

[2] Taylor, P., Ganapathy, S. P., Natarajan, J., and Gunasekaran, A. (2014), "Influence of eco-innovation on Indian manufacturing sector sustainable performance", International Journal of Sustainable Development \& World Ecology, Vol. 6, pp, 37-41. https://doi.org/10.1080/13504509.2014.907832.

[3] Chen Jian, (2006). "RFID based Management Information System Design and Implementation", Electronics University of Science and Technology.
[4] Abbasi, M., and Nilsson, F. (2016), "Developing environmentally sustainable logistics. Exploring themes and challenges from a logistics service providers' perspective", Transportation Research Part D: Transport and Environment, Vol. 46, No. 2, pp. 273-283. https://doi.org/10.1016/j.trd.2016.04.004.

[5] Mohan, N., Panda, S., Sankar, S., and Basu, M. (2017), "ScienceDirect Corporate social responsibility, coordination and profit distribution in a dual-channel supply chain", Pacific Science Review, Vol. 16, No. 14, pp. 235-237.

[6] Bo Yan, Danyu Lee, (2009). "Application of RFID in Cold Chain Temperature Monitoring System", ISECS International Colloquium on Computing, Communication, Control, and Management PP: 258-261.

[7] Lee, A. H. I., Chen, H. H., and Chen, S. (2015), "Suitable organization forms for knowledge management to attain sustainable competitive advantage in the renewable energy industry" Energy, Vol. 89, No. 21, pp 1057-1064. https://doi.org/10.1016/j.energy.2015.06.047.

[8] Loc Ho, Melody Moh, Zachary Walker, Takeo Hamada, Ching-Fong Su, (2005). "A Prototype on RFID and Sensor Networks for Elder Healthcare: Progress Report", in: Proceedings of the 2005 ACM SIGCOMM workshop on Experimental approaches to wireless network design and analysis.

[9] Mateusz Malinowski, Mattew Moskwa, Mark Feldmeier, Mathew Laibowitz, Joseph A. Paradiso, (2007). "CargoNet: A Low-Cost MicroPower Sensor Node Exploiting Quasi-Passive Wakeup for Adaptive Asynchronous Monitoring of Exceptional Events", SenSys'07, November 6-9, Sydney, Australia.

[10] Zhen Zhen, Wang Fei, Xia Xiang, (2007). "RFID-based real-time wireless temperature monitoring system design and implementation", Engineering Technology.

[11] Khademian, A., and Bagherpour, R. (2017), "Environmentally sustainable mining through proper selection of explosives in blasting operation", Environmental Earth Sciences, Vol. 76, No. 4, pp. 128-147. https://doi.org/10.1007/s12665-017-6483-2. 